\title{
Uma breve introdução a discussão sobre as pinturas rupestres brasileiras
}

\section{A brief introduction to the discussion about the brazilian cave paintings}

\section{Michel Justamand}

Doutor em Ciências Sociais/Antropologia pela PUC/SP. Professor do Departamento de História da Arte - DHA, da Universidade Federal de São Paulo - UNIFESP/campus Guarulhos e Professor Permanente do Programa de Pós-Graduação em Sociedade e Cultura na Amazônia - PPGSCA, da Universidade Federal do Amazonas - UFAM.

Email: micheljustamand@yahoo.com.br

\section{Vitor José Rampaneli de Almeida}

Doutorando em Planejamento e Gestão do Território - UFABC. Docente da Fundação Escola de Comércio Álvares Penteado - FECAP,

E-mail: vitor.almeida@ufabc.edu.br

\section{Gabriel Frechiani de Oliveira}

Doutor em Arqueologia pela Universidade Federal de Sergipe - UFS e Docente da Secretaria de Educação do Estado do Piauí - SEDUC/PI,

E-mail: gfrechiani@hotmail.com

\section{Leandro Paiva}

Historiador (UNIRIO), pós-graduado em Arqueologia (Claretiano) e Mestrando em Antropologia Social - PPGAS/UFAM.

E-mail: professorleandropaiva@gmail.com

\section{RESUMO}

Este trabalho apresenta uma breve discussão sobre as pinturas rupestres (pinturas feitas nas rochas) produzidas no Brasil. Esta prática remete-se há milhares de anos antes do presente em solo nacional. Desta maneira sugerindo que a História da presença humana no território brasileiro teria muito mais de 500 anos, ao contrário da "crença oficial" de que o país teria sido "descoberto" em 1500 pelos aventureiros portugueses.

Palavras-chave: Pinturas rupestres; Brasileiras; Parque Nacional Serra da Capivara; Piauí.

\section{ABSTRACT}

This work presents a brief discussion of cave paintings (paintings made on rocks) produced in Brazil. This practice dates back thousands of years before the present on national soil. In this way, suggesting that the history of human presence in Brazilian 
territory would be much more than 500 years old, contrary to the "official belief" that the country would have been "discovered" in 1500 by Portuguese adventurers.

Keywords: Rock paintings; Brazilians; Serra da Capivara National Park; Piauí.

\section{INTRODUÇÃO}

As pinturas rupestres, em muitas de suas cenas, espalhadas por quase todos os estados do país, apontam, segundo nosso ponto de vista, o modo de vida dos primeiros habitantes da terra brasilis. Modo de vida que foi muito rico e deixou nas cenas rupestres suas marcas da memória ancestral. Entre elas estão cenas de lutas em duplas, sociais ou coletivas, podemos observar também a sexualidade da época, algumas práticas cotidianas como as caçadas, as coletas, as amamentações, algumas formas lúdicas. Há ainda cenas de animais em movimentos, algumas relacionadas com os grupos humanos. E também se notam cenas de plantas, arvores em especial.

Dessa forma pretendemos apresentar algumas cenas inscritas nas rochas e a partir delas refletir sobre a História da presença humana no território brasileiro mais ancestral. Partindo de ideias de autores que já se debruçaram sobre a temática indígena, artística e ou outras que se relacionam, segundo nosso ponto de vista, com as inscrições rupestres, especialmente no que diz respeito a formas de comunicação desses primeiros habitantes do Brasil.

\section{MEMÓRIA E HISTÓRIA ANCESTRAL}

As pinturas rupestres como forma de resgate da memória cultural de um ou mais grupos dos primeiros habitantes do Brasil têm sido objeto de estudos e de debates. A memória cultural também ocorre por meio da grafia-desenho, a maneira de guardar a síntese do desenvolvimento, que consiste em escrever através de símbolos, traços, formas e deixar registrado no barro, no traçado de uma folha de palmeira transformado em cestaria, na parede e até no corpo. E, também, através de pinturas feitas com jenipapo e urucum ${ }^{1}$. As pinturas rupestres produções dos grupos ancestrais se enquadrariam nessa condição citada acima igualmente. Elas teriam as funções de preservação das memórias e história dos grupos em suas cenas plasmadas nas rochas.

1JECUPÉ, Kaka Werá. A terra dos mil povos, p. 26. 
Os arqueólogos têm papel importante na revelação dessas cenas para a maior parte da nação que ainda as desconhece. E contribuiriam para a construção da memória dos primeiros povos, ainda muito combalida e esquecida por grande parte dos habitantes atuais das terras brasilis.

Assim a tarefa principal do arqueólogo seria fazer os objetos falarem, dizerem de si mesmos e dos homens que os fabricavam. Por meio da arqueologia é possível saber como se deu o desenvolvimento da tecnologia, os modos de adaptação a natureza, o aproveitamento dos recursos naturais, o desenvolvimento da arte, a dispersão de grupos, os contatos entre culturas diferentes ${ }^{2}$.

A historiadora Loredana Marise R. Ribeiro, discutindo a tradição e as rupturas na arte rupestre de Minas Gerais, fala de reaproveitamento dos grafismos por vários grupos, para a autora essas figuras eram reutilizadas e as relações entre grafismos que perduram em meio às diferentes ocupações estilísticas dos suportes do sítio apontam para o manejo e compartilhamento de bens culturais por grupos étnicos distintos ${ }^{3}$.

Parece-nos que esse reaproveitamento mostra um compartilhar e integrarse com o que já estava à disposição nos abrigos usados por grupos anteriores. Trata-se, portanto, de grupos que se mestiçaram culturalmente ${ }^{4}$.

Mário Pedrosa identifica nas pinturas rupestres "forças humanas" e "significado mágico". Pedrosa descreve que mesmo no Brasil se conhecem desenhos na pedra a beira dos rios, que são relativamente arranhados na rocha, como uma espécie de gravura. Eles são em parte de figuras geométricas e também formas humanas. Acredita-se, que, o ponto de partida dos desenhos eram riscos que o atrito da corda de que se serviam os selvagens ao puxar a canoa para a margem produzida na pedra. A esses desenhos foram acrescentadas interpretações de significado mágico ${ }^{5}$.

Para Pedrosa comenta também sobre as representações de animais vistos nas figuras, ditas primitivas, produzidas nas rochas. Nessas obras, estariam as

2IDEM, ibidem, p. 30.

${ }^{3}$ RIBEIRO, Loredana M. R. "Tradição e ruptura na arte rupestre da Lapa do Gigante / MG", Revista CLIO, série arqueológica, $n^{\circ}$ 12, p. 182.

4JUSTAMAND, Michel. As pinturas rupestres no Brasil: uma discussão atual. In: SOUZA, Edgar e GRILLO, José Geraldo Costa (orgs.). Olhares sobre a História do Brasil. São Paulo: Primeira Impressão, 2008, p. 14.

${ }^{5}$ PEDROSA, Mário. Forma e percepção estética, p. 216. 
mais célebres representações de animais da arte das cavernas, as formas ditadas pelos acidentes naturais dos muros e rochas foram completadas para nos dar figuras de extraordinária energia 6 .

Para Fayga Ostrower os artistas rupestres usaram-se das conformações rochosas naturais. Eles aproveitavam certas cavidades ou saliências que pudessem sugerir as formas do animal. E gravavam nos sulcos das linhas de contorno, colorindo as áreas com pigmentos naturais: terra, que são os tons de ocre, óxido de ferro para o vermelho, carvão para o preto ${ }^{7}$. Para a autora, em certas pinturas, os animais representariam também os ancestrais. As cenas com animais continham um duplo significado: ao mesmo tempo em que era necessário matá-los para sobreviver, eles também representavam figuras ancestrais dos homens $^{8}$. A autora acredita ainda que por meio das imagens os humanos dominariam e possuiriam tais animais. Acrescenta também que a atitude que os desenhos transmitem é do mais profundo respeito para com os animais conhecidos e reconhecidos inscritos nas rochas de então ${ }^{9}$.

\section{ASPECTOS RELEVANTES DAS PINTURAS RUPESTRES}

Outros aspectos relevantes é que as pinturas rupestres oferecem aos pesquisadores são os hábitos diários e os eventos diferenciados na vida social dos grupos. Assim, algumas representações humanas são apresentadas revestidas de atributos culturais, tais como enfeites de cabeça, objetos cerimoniais nas mãos, etc. As composições de grafismos representando ações ligadas sejam à vida de todos os dias, seja à cerimonial, são abundantes e constituem a especificidade da tradição Nordeste ${ }^{10}$.

Os humanos precisavam compreender e articular o mundo que o cercava em seu próprio benefício e, para isso, utilizou as pinturas rupestres.

Os paleolíticos, articulando o seu mundo por imagens, incentivados por necessidades peculiares, imaginava conceitos em forma plástica para (re)

6IDEM, ibidem, p. 216.

7OSTROWER, Fayga. A construção do olhar, p. 168.

8IDEM, ibidem, p. 168.

9IDEM, ibidem, p. 169.

10FUNDHAM. Revista Parque nacional Serra da Capivara PI-Brasil, p. 62. 
conhecer, (re) processar e (re) armazenar o seu lugar circundante, pois disso dependia a sua vida ${ }^{11}$.

A atividade pictórica no início teve uma função individual e lúdica, e dessa forma tornou-se um procedimento com função social ${ }^{12}$. As pinturas rupestres teriam sido um fator que contribuiria para o relacionamento social comum a todos que participavam da cultura local naquele determinado espaço tempo.

As pinturas rupestres estão espalhadas por todo o mundo conhecido e foram produzidas quase que ao mesmo tempo, fato que atesta a sua importância sociocultural para os habitantes locais e para os grupos que estivessem de passagem por aqueles caminhos. Conforme revelam as mais recentes descobertas confirmando que os registros rupestres pré-históricos apareceram de maneira quase que concomitante, na Europa, América, África e Austrália. A universalidade dessa atividade não ligada às técnicas de subsistência indica a importância sociocultural dos registros rupestres no desenvolvimento das sociedades pré-históricas ${ }^{13}$.

Existem algumas possibilidades de uso (como: controle dos recursos naturais, roteiros das caminhadas, indicação dos locais para explorar) das pinturas pela sociedade produtora. Assim, a distribuição da arte rupestre indicaria um nível significante de controle dos recursos naturais por parte das populações que a brotaram. As suas localizações se constituiriam em apropriadas rotas de conexão entre estas áreas de exploração de recursos naturais e de indicação de locais especiais de exploração de determinados recursos ${ }^{14}$.

\section{PARA QUE SERVIRIAM AS PINTURAS RUPESTRES?}

No Brasil, os arqueólogos vêm apontando para a possibilidade de as manifestações rupestres terem servido para os grupos se comunicarem, ou mesmo para que outras populações que chegaram no mesmo lugar, algum tempo

\footnotetext{
${ }^{11}$ OLIVEIRA, Anna Claudia de. Neolítico: arte moderna, p. 55.

${ }^{12}$ PESSIS, Anna-Marie. Pré-História do Parque Nacional Serra da Capivara. I.n: Pré-História da Terra Brasilis, p. 69.

${ }^{13}$ PESSIS, Anna-Marie \& GUIDON, Niéde. Registros rupestres e caracterização das etnias pré-históricas. In: VIDAL, Lux. Grafismo indígena, p. 19.

${ }^{14}$ SILVA, Fabíola Andréa. A pesquisa sobre arte rupestre: uma introdução aos seus princípios básicos, Revista do CEPA, p. 19.
} 
depois, as usassem como "modelos", pintando por cima delas e/ou "completandoas"15.

Guidon e Pessis indicam a existência, provável, de significados diversos interpretativos para as mesmas cenas. E, também, que para pinturas diversas, alguns significados iguais. Assim, duas culturas diferentes poderiam representar uma mesma ideia, mas utilizando dois grafismos diferentes. Para elas, ainda uma mesma forma pode ter tido significados diferentes em contextos de usos sociais diferentes ${ }^{16}$.

Assim, parece-nos que as culturas intercambiavam e se relacionavam para conseguirem entender os sinais produzidos pelos grupos diferentes. Se, em outro momento, uma mesma pintura tem interpretação diferente em cada grupo, é sinal de que as populações trocaram informações e a reutilizaram de outras maneiras ${ }^{17}$.

Com frequência as figuras da tradição Agreste foram realizadas no interior de painéis da Nordeste, o que dificultou os trabalhos na segregação das tradições pelos arqueólogos. Guidon afirma que é muito comum se deparar com grafismos desta tradição superpostos a grafismos de outras tradições. $O$ estudo deste procedimento de superposição permitiu identificar a existência de um critério de escolha do espaço pictural que é próprio da tradição do Agreste quando ela partilha um espaço material com a tradição Nordeste ${ }^{18}$.

Entendemos que "partilhar" um espaço entre as tradições significa que aquelas populações dividiram experiências, conhecimentos e informações em um mesmo espaço, provavelmente, mesmo que em períodos diferentes. Dessa forma, as pinturas rupestres poderiam ter sido responsáveis por transmitir "sugestões", informações e indicações de como viver naquele determinado local.

Parece-nos que esses locais eram, em grande parte, recorrentemente, reocupados, pois estavam carregados de informações sobre o entorno no qual se encontram. Consequentemente, os novos ocupantes poderiam decodificar tais

\footnotetext{
15JUSTAMAND, Michel. As pinturas rupestres no Brasil: uma discussão atual. In: SOUZA, Edgar e GRILLO, José Geraldo Costa (orgs.). Olhares sobre a História do Brasil. São Paulo: Primeira Impressão, 2008, p. 19.

${ }^{16}$ PESSIS, Anna-Marie. \& GUIDON, Niéde. Registros rupestres e caracterização das etnias préhistóricas. In: VIDAL, Lux. Grafismo indígena, p. 28.

17JUSTAMAND, Michel. As pinturas rupestres no Brasil: uma discussão atual. In: SOUZA, Edgar e GRILLO, José Geraldo Costa (orgs.). Olhares sobre a História do Brasil. São Paulo: Primeira Impressão, 2008, p. 19.

${ }^{18}$ GUIDON, Niéde. As ocupações pré-históricas do Brasil. In: CUNHA, Manuela Carneiro da. História dos Índios no Brasil, p. 46.
} 
recomendações deixadas inscritas nas rochas. Os principais sítios localizavam-se em abrigos rochosos, grutas e cavernas e indicam certa estabilidade de (re) ocupação, tanto nas camadas sedimentares quanto nas pinturas das paredes ${ }^{19}$.

Temos como certo que era importante conhecer os meios de subsistência, para não perder demasiado tempo diariamente em busca da comida (caça/pesca e/ou coleta de frutas). Por isso, as pinturas rupestres tiveram o papel de retratar, com alguma precisão, qual era a base econômica, nos locais onde foram desenhadas e informar o que havia naquele meio. Por esse motivo, imagina-se que o alicerce fundamental dos grupos continuava sendo a caça, a coleta e a pesca. As pinturas rupestres retratavam esses detalhes com certa precisão. O que permiti observar a evolução sociocultural desses grupos durante pelo menos 6 mil anos. Desta forma, as inscrições em rochas feitas há milhares de anos, no Parque Nacional Serra da Capivara, em São Raimundo Nonato se constituem num dos mais longos e importantes arquivos visuais sobre da Humanidade, disponível, ainda hoje, no mundo 20 .

A produção rupestre permitia a ocorrência das trocas de ideias, técnicas e práticas e que essas fossem incorporadas às sociedades que não as tinham, mas que partilharam os mesmos espaços socioculturais e criaram novas formas de expressão. Sendo que durante o período inicial das produções artísticas nas rochas, a região era pouco habitada. Então, outros grupos, minoritários, partilharam o mesmo espaço junto às comunidades culturais já instaladas na Serra da Capivara. Os grupos que não tinham o domínio da técnica gráfica incorporaram às suas culturas esta prática rupestre emanadas das comunidades antecessoras. Estas outras populações que chegaram depois teriam sido as responsáveis por outro e novos modos de inscrições nas rochas ${ }^{21}$.

\section{QUAIS ERAM AS FUNÇÕES DAS PINTURAS RUPESTRES?}

O surgimento da pintura rupestre deve ter sido um acontecimento natural em nossa evolução. As pinturas rupestres seriam as representações gráficas da

\footnotetext{
${ }^{19}$ SCHMITZ, Pedro I. A questão do paleolítico. In: TENÓRIO, Maria Cristina. Pré-História da Terra Brasilis, p. 57.

${ }^{20}$ GUIDON, Niéde. As ocupações pré-históricas do Brasil. In: CUNHA, Manuela Carneiro da. História dos índios no Brasil, p. 43.

${ }^{21}$ PESSIS, Anna-Marie. Apresentação gráfica e apresentação social na tradição Nordeste de Pintura rupestre do Brasil. Revista CLIO no 5, p. 14 e 15.
} 
linguagem falada ou gestual dos grupos ancestrais. Havendo, evidentemente, comunicação e história, isso desde muito tempo atrás em terras brasilis. O surgimento da arte representaria, portanto, algo normal dentro da evolução física, mental e sensorial do Homo Sapiens: surgindo da formação do conjunto intelectual linguagem-grafismo, significando a representação gráfica da "magia" da linguagem ${ }^{22}$.

Existiria mais de uma função para as pinturas rupestres. E acreditar em uma única função é o mesmo que limitar a capacidade humana. Tendo como certo que a função essencial da pintura rupestre era esclarecer e provocar ações. Acreditamos que nas sociedades primitivas a função essencial da arte não é fazer magia, mas esclarecer e provocar ações. Contudo esta base mágica não pode ser negada, pois em todas as suas formas a arte sempre possui um pouco de magia: "a arte é necessária para que o homem se torne capaz de conhecer e mudar o mundo. Mas a arte também é necessária em virtude da magia que the é inerente"23.

A arte rupestre, em sua forma pintada, pois se pode encontrar também gravuras, funcionaria como promotora da capacidade do homem de "conhecer e mudar o mundo", considera-se que o homem poderia, por meio de seus conhecimentos culturais adquiridos, transformar aquilo que conhece e mudar para melhorar a sua vida ${ }^{24}$. Vale ressaltar ainda outra possível função das pinturas rupestres seria muito difícil de acreditar que as sociedades, quaisquer que fossem elas, não teriam suas próprias formas de marcar o tempo 25 .

As pinturas rupestres pode ser que mostrassem os locais de moradia, de rituais e de sociabilização dos grupos usuários. Qualquer usuário poderia identificar sem erro, nem problemas, o "paredão das araras", onde existe o melhor material para fazer instrumentos de pedra. Poderiam ainda identificar o imenso salão coberto da "mulher pintada", onde cabia todo o bando para a estação das chuvas. E mais a aldeia junto ao "lajedo das cobras", onde o moço agricultor tinha de escolher a sua noiva, segundo Schmitz ${ }^{26}$. As inscrições nas rochas poderiam

22SEDA, Paulo. A questão das interpretações em arte rupestre no Brasil. Revista CLIO no 12, p. 150. ${ }^{23}$ SEDA, Paulo. A questão das interpretações em arte rupestre no Brasil. Revista CLIO no 12, p. 150. 24JUSTAMAND, Michel. As pinturas rupestres no Brasil: uma discussão atual. In: SOUZA, Edgar e GRILLO, José Geraldo Costa (orgs.). Olhares sobre a História do Brasil. São Paulo: Primeira Impressão, 2008, p. 22.

${ }^{25}$ SEDA, Paulo. A questão das interpretações em arte rupestre no Brasil. Revista CLIO nํ 12, p.160.

${ }^{26}$ SCHMITZ, Pedro I. Arte rupestre no centro do Brasil, p. 31. 
ter servido para marcar e delimitar o território de cada um dos grupos nômades ${ }^{27}$. Isto é indicativo de que os antigos habitantes do local também estavam preocupados com seus limites territoriais, com suas "propriedades" coletivas, como garantia de sobrevivência.

\section{O QUE MOSTRAM AS CENAS RUPESTRES?}

Niède Guidon aponta que como todos os povos, os antigos habitantes de São Raimundo Nonato deixaram vestígios de suas crônicas sociais e diárias. Esses vestígios ficaram registrados nas pinturas rupestres. A arte figurativa com cenas e representações mais reconhecíveis só veio aparecer depois, com representações de plantas, figuras humanas ${ }^{28}$, objetos feitos pelo homem, figuras geométricas de significado ignorado, e desenhos de capivaras, seriemas, onças, tatus e cervídeos (Figura 1). Algumas pinturas mostram cenas de caça, combates, lutas individuais ${ }^{29}$, execuções ${ }^{30}$, relações sexuais - algumas caracterizadas pela presença de um observador - e partos ${ }^{31}$. Outras representam cerimônias de significado ignorado ${ }^{32}$, nas quais se veem homens ornados com grandes cocares de penas; filas de pessoas comandadas por um tocador de trompa e figuras com maracás (instrumentos chacoalhantes) nas mãos ${ }^{33}$.

\footnotetext{
${ }^{27}$ IDEM, ibidem, p. 31.

28JUSTAMAND, Michel. O Brasil desconhecido: as pinturas rupestres de São Raimundo Nonato - Piauí. Rio de Janeiro: Achiamé, 2010, p. 53.

${ }^{29} \mathrm{JUST}$ AMAND, Michel. As relações sociais nas pinturas rupestres. Embu das Artes: Alexa Cultural, 2007, p. 32.

30JUSTAMAND, Michel. Pinturas rupestres do Brasil: uma pequena contribuição. Embu das Artes: Alexa Cultural, 2007, p. 23.

${ }^{31}$ JUSTAMAND, Michel. A mulher rupestre: representações do feminino nas cenas rupestres de São Raimundo Nonato - Piauí. Embu das Artes: Alexa Cultural, 2014, p. 29.

32JUSTAMAND, Michel. As pinturas rupestres na História e na Antropologia: uma breve contribuição. Francisco Morato: Margê, 2005, p. 29-40.

${ }^{33}$ GUIDON, Niède. Pré-História do Piauí. Revista Horizonte Geográfico no 12, p. 42.
} 


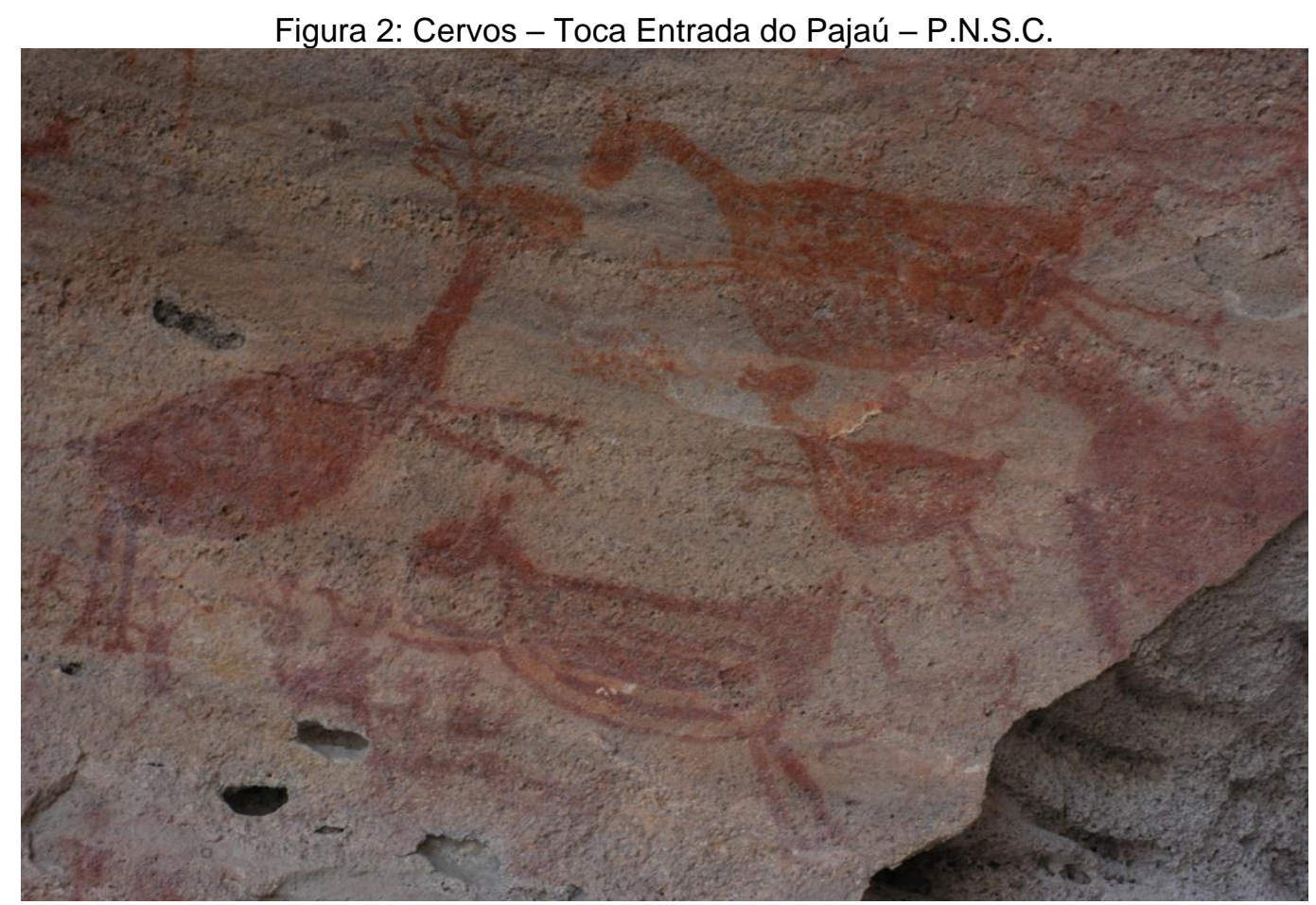

Fonte: Acervo pessoal dos autores.

Os habitantes de muito antes de 1500 pintavam nas cavernas e paredões o que observavam de mais interessante à sua volta, durante suas vidas. Dessa forma, fortaleciam as transmissões dos ensinamentos e conhecimentos acumulados ${ }^{34}$. Assim, todos aprendiam a reconhecer os costumes da cultura local da época.

\section{ALGUMAS INTERPRETAÇÕES SOBRE AS PINTURAS RUPESTRES}

A atitude natural das pessoas ao se depararem com os painéis das pinturas rupestres é procurar um significado imediato, ou seja, procurar "ler" o que está ali escrito ou o que se pretendeu contar, segundo Gabriela Martin ${ }^{35}$. E a tendência atual entre os arqueólogos é não interpretar as representações rupestres, apenas descrever o que há ali inscrito. Mas descrever o que se nota ali inscrito pode ser também um ato de interpretação, nos parece. Martin esclarece que é o objetivo de alguns arqueólogos apenas descrever o que se pode "ver". Procedendo-se a análises mais técnicas do que interpretativas, utilizando-se critérios técnicos que valorizam o saber como os grafismos foram realizados, os recursos materiais

\footnotetext{
34JUSTAMAND, Michel e GRISOLIO, Lilian Marta. Reflexões acerca das políticas educacionais no Brasil: de 1500 à atualidade. In: JUSTAMAND, Michel e GRISOLIO, Lilian Marta. Políticas educacionais: o projeto neoliberal em debate. Embu das Artes: Alexa Cultural, 2007, p. 35. ${ }^{35}$ MARTIN, Gabriela. Pré-História do Nordeste do Brasil, p. 248.
} 
empregados e, principalmente, quais os grafismos que podem ser considerados como representativos de um estilo rupestre determinado ${ }^{36}$. Não é assim que vemos. Imaginamos que os artistas ancestrais tinham intencionalidades com as suas obras. E que essa intenção ainda pode ser de alguma forma capta. Isso por que temos as mesmas condições mentais, temos os mesmos sentimentos afetivos e temos muitas emoções correlatas às imagens como as que tínhamos há milhares de anos atrás quando das inscrições nas rochas de São Raimundo Nonato e de outras espalhadas pelo mundo.

Portanto, entendemos que mesmo a ciência arqueológica tendo muita contribuição a oferecer no que diz respeito às datações, ao contexto dos sítios arqueológicos e às pigmentações, não faz interpretações, somente descreve tecnicamente as pinturas ${ }^{37}$. Mas nem todos envolvidos com o conhecimento arqueológico pensam da mesma forma.

Há outra tendência, da qual um dos autores já foi citado, que procura sim interpretar, mesmo que de forma hipotética, como é ocaso de Pedro Inácio Schmitz.

Cabe-nos, ainda citar, um artigo, de Leila Maria Serafim Pacheco e Paulo T. de Souza Albuquerque, intitulado: O lajedo Soledade: um estudo Interpretativo. Trata-se de um estudo que aponta para a necessidade de interpretações daquele local no Rio Grande do Norte, permitindo abrir as portas para novas pesquisas de interpretações das pinturas rupestres. Outros artigos também são citados nesta pesquisa, como o da Fabíola Andréa Silva, que trata da questão das interpretações no mundo.

\section{AS PINTURAS RUPESTRES TINHAM FUNÇÕES PEDAGÓGICAS?}

De toda forma, apesar de ser contra as interpretações, Martin explica que existiam redes de comunicação social pelas quais haveria transmissão das informações através das gerações ${ }^{38}$. Logo, as pinturas rupestres eram passíveis de serem ensinadas para os grupos futuros e teriam a capacidade de agregar socialmente o grupo, que entenderia o legado deixado. Era como se eles tivessem

\footnotetext{
${ }^{36}$ IDEM, Ibidem, p. 248.

37JUSTAMAND, Michel. As pinturas rupestres no Brasil: uma discussão atual. In: SOUZA, Edgar e GRILLO, José Geraldo Costa (orgs.). Olhares sobre a História do Brasil. São Paulo: Primeira Impressão, 2008, p. 26.

${ }^{38}$ MARTIN, Gabriela. Pré-História do Nordeste do Brasil, p. 308.
} 
participado de uma "escola rupestre", onde aprendiam e depois transmitiam suas mensagens. Esta agregação permitiria aos grupos usuários a sobrevivência econômica, cultural e social ${ }^{39}$.

Assim, as pinturas rupestres, produzidas de acordo com o que se observava no local circunvizinho, eram portadoras e capazes de transmissão de sentido, como signos que se transformam uns nos outros, ad infinitum, na mentalidade humana.

Segundo o conceito peirceano de signo, se existe comunicação é porque há história também, pois gesto palavra, imagem e/ou oralidade têm o mesmo valor funcional de transmissão de comunicação, que independe da materialidade. As pinturas rupestres, então, seriam signos não verbais que agiriam da mesma forma que os verbais na transmissão dos conhecimentos ${ }^{40}$.

Já segundo Guidon as pinturas rupestres apresentam figuras humanas que caminham, pulam, correm, dançam com movimentos graciosos, lançam dardos ou atacam com bordunas ou machados. Parece-nos que a autora se apropriou de interpretações atuais dos "atos vistos" nas cenas rupestres da Serra da Capivara. A autora continua sua explanação descrevendo que algumas formas humanas representadas nas cenas são estáticas mais revelam uma expressão emocional pela posição dos braços da cabeça e do corpo ${ }^{41}$. É como acreditamos também. As imagens rupestres são de fácil identificação do que se deseja mostrar em seus contornos, atributos e formas representadas. Sugerimos que, por estes motivos, as pinturas teriam possibilitado maior relação (um percurso de compreensão, de aprendizagem e de utilização) entre os indivíduos da sociedade e todo o meio -social e biológico -- circundante.

Martin caracteriza, especialmente, a Tradição Nordeste pela presença de certas composições gráficas, grafismos de ação, que representam ações da vida cotidiana e cerimonial. São temas sexuais, de violência, de caça, e rituais cerimoniais cujos componentes e distribuição persistem nas diversas

\footnotetext{
39JUSTAMAND, Michel. As pinturas rupestres no Brasil: uma discussão atual. In: SOUZA, Edgar e GRILLO, José Geraldo Costa (orgs.). Olhares sobre a História do Brasil. São Paulo: Primeira Impressão, 2008, p. 26.

40JUSTAMAND, Michel. As pinturas rupestres no Brasil: uma discussão atual. In: SOUZA, Edgar e GRILLO, José Geraldo Costa (orgs.). Olhares sobre a História do Brasil. São Paulo: Primeira Impressão, 2008, p. 27.

${ }^{41}$ MARTIN, Gabriela. Casa Santa: um abrigo com pinturas rupestres do estilo Seridó, no Rio Grande do Norte, Revista CLIO no 5, p. 56.
} 
manifestações gráficas desta tradição no Nordeste do Brasil|22. Observar que lembram ações da vida cotidiana é uma forma de interpretar as imagens ali plasmadas, ao menos nos parece.

Entre as tradições de pinturas rupestres identificadas na região, a tradição Nordeste é a mais importante e se caracteriza por estar composta de figuras humanas e animais, frequentemente arranjados de modo a representar ações da vida cotidiana e cerimonial, do homem na pré-história (Figura 2). Estas representações gráficas são reconhecíveis por qualquer observador, segundo Pessis $^{43}$. É exatamente como pensamos e salientamos acima.

Figura 2: Tradição Nordeste - Sítio Toca da Entrada do Baixão da Vaca - Parque Nacional Serra da Capivara (PI).

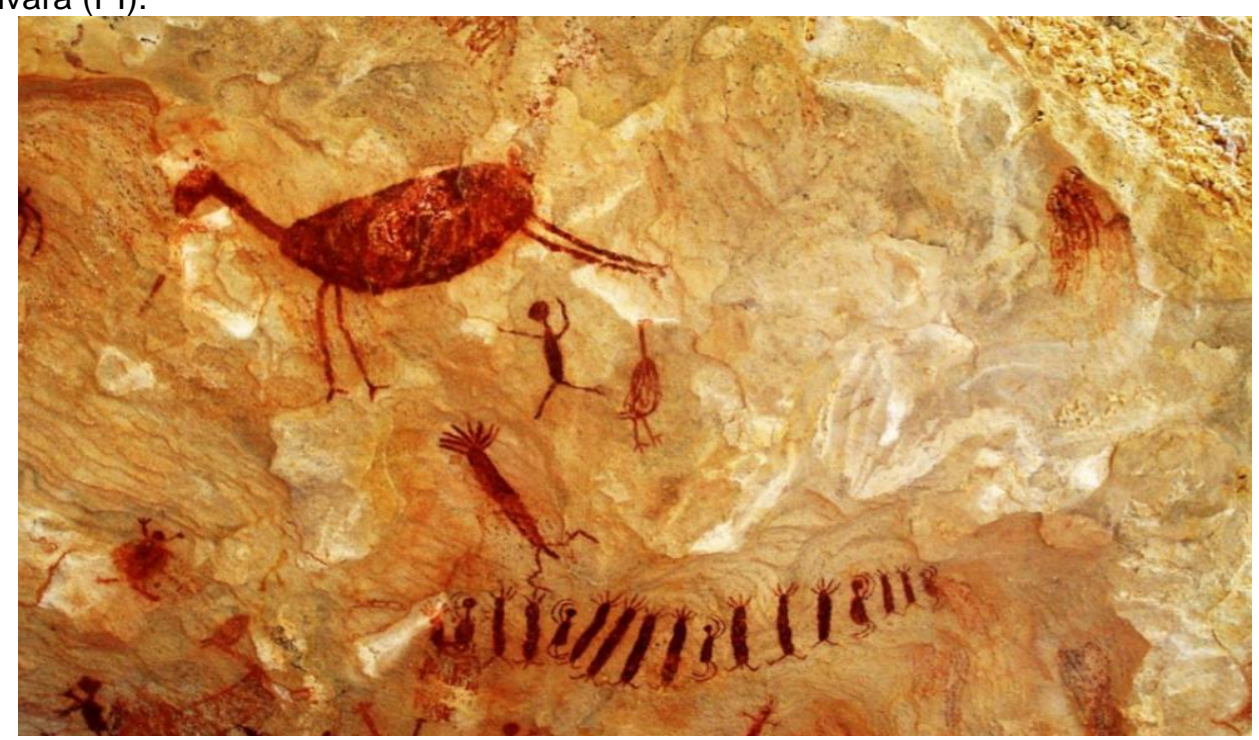

Fonte: Acervo FUMDHAM.

Ações que representam o cotidiano eram sinais de que as pinturas, provavelmente, foram para os antigos habitantes do Brasil (de modo nacional e não só para o Nordeste) um indicativo de atitudes a tomar e em que momento, nas suas práticas sociais e culturais ${ }^{44}$.

Pessis e Guidon apontam que um dos traços mais marcantes das inscrições rupestres é o fato de que esses grafismos podem estar agenciados, representando ações. Os temas dessas ações podem ser reconhecidos, na

\footnotetext{
${ }^{42 M A R T I N, ~ G a b r i e l a . ~ A ~ s u b t r a d i c ̧ a ̃ o ~ S e r i d o ́ ~ d e ~ p i n t u r a ~ r u p e s t r e ~ p r e ́-h i s t o ́ r i c a ~ d o ~ B r a s i l, ~ R e v i s t a ~ C L I O ~}$ no 5 , p.21.

${ }^{43}$ PESSIS, Anna-Marie. Apresentação gráfica e apresentação social na tradição Nordeste de pintura rupestre do Brasil, Revista CLIO no 5, p. 11.

44JUSTAMAND, Michel. As relações sociais nas pinturas rupestres. Embu das Artes: Alexa Cultural, 2007, p. 39-42.
} 
maioria dos casos, estando ligados a técnicas de subsistência e atividades cotidianas ou cerimoniais (Figura 3$)^{45}$.

Figura 3: Provável cena de ação cerimonial - Parque Nacional Serra da Capivara (PI) - Sítio Toca da Entrada do Baixão da Vaca.

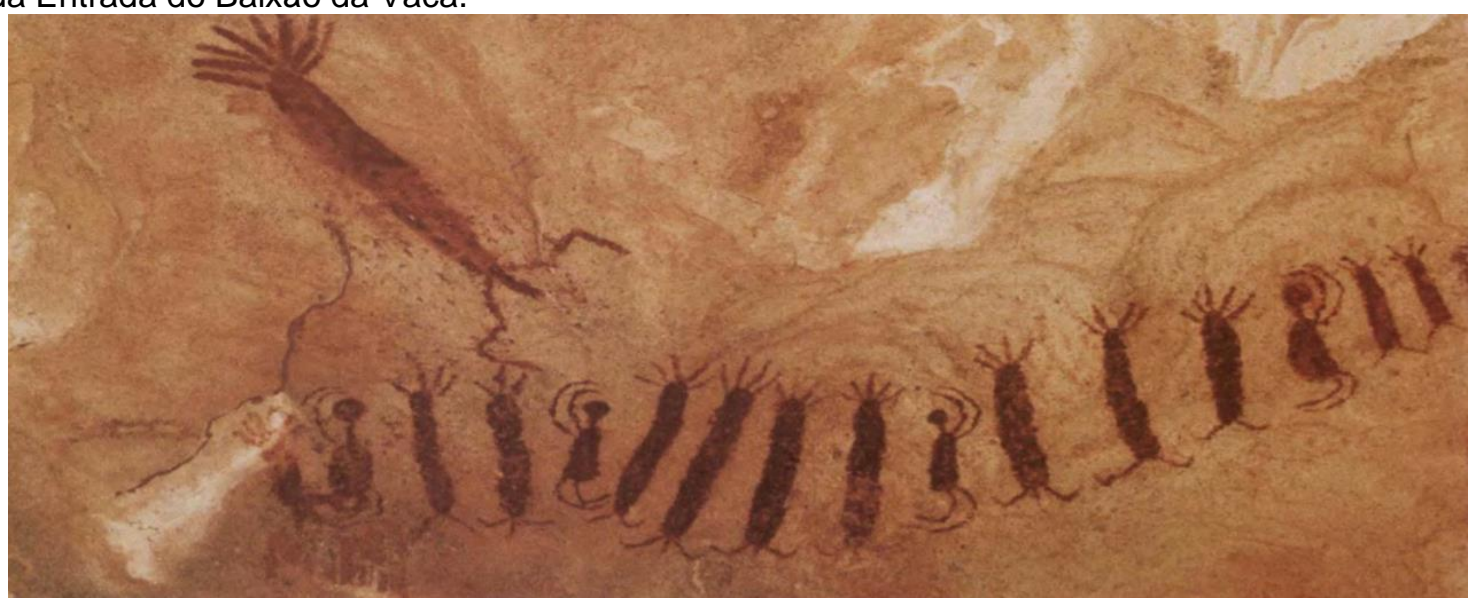

Fonte: Pessis (2003).

As atividades de subsistência presentes nas pinturas são as mais importantes, pois a partir da produção alimentícia e da saúde social transmitemse os conhecimentos que influenciaram nos hábitos de caça e coleta dos grupos.

O significado contido nas pinturas e gravuras rupestres, ordenadas pelos povos pré-históricos, ficou perdido no tempo. O que antes foi uma epístola percebida e dividida por muitos, hoje nos é impossível desvendar. No entanto, a forma concebida e plasmada na rocha conservou-se ao longo dos séculos, chegando até os nossos dias como um depoimento da expressão cultural de um ou mais povos. Nesse sentido, parece-nos importante conservar e divulgar esse patrimônio arqueológico. E temos como certo que é dever de cada um contribuir nessa divulgação ${ }^{46}$.

\section{CONSIDERANDO FINALMENTE...}

As pinturas rupestres trazem para o historiador, mas não só para ele, a possibilidade de imaginar e de ver/constatar/transmitir para outros os saberes preservados nas cenas rupestres. E por meio das interpretações (ou mesmo insinuações) da arqueologia e da antropologia, poderemos ver como era o mundo,

${ }^{45}$ PESSIS, Anna-Marie. \& GUIDON, Niéde. Registros rupestres e caracterizações das etnias préhistóricas, in: VIDAL, Lux. In: Grafismo Indígena, p.23.

${ }^{46}$ PEREIRA, Edithe. Arte da Terra: resgate da cultura material e iconográfica do Pará, p. 20. 
o meio ambiente e o cotidiano em que viviam os homens e mulheres dos grupos que ocuparam as terras brasilis em tempos ancestrais.

As pinturas rupestres têm importância social e histórica para a comunicação humana. Sugerem uma forma de transmissão sistemática de informações grafadas e se encontram dispersas por todo o território brasileiro e estão presentes também em todos os continentes. Seu desenvolvimento segue determinadas padronizações, cuja repetição e/ou diferenciação possibilita a identificação e algumas vezes até a sua caracterização sociocultural. São vestígios intencionais deixados pelos humanos, como já observamos, no mundo inteiro. Logo, são passíveis de serem usadas como matéria de estudos por estudantes das séries iniciais das escolas e por todos os tipos de historiadores, além, é claro, de outras ciências afins, como a comunicação.

Para Ciro F. Cardoso todos os vestígios do passado são considerados matéria para o historiador. Desta forma, novos textos, tais como a pintura, o cinema, a fotografia etc., foram incluídos no elenco de fontes dignas de fazer parte da história e passíveis de leitura por parte do historiador ${ }^{47}$.

Não podemos deixar de lado saberes acumulados ao longo de milhares de anos. Saberes que foram transmitidos para as gerações daquele período, mas que podem ainda hoje apresentar informações interessantes sobre a vida dos nossos ancestrais que, talvez, servissem de exemplos para a nossa vida atualmente.

${ }^{47}$ CARDOSO, Ciro Flamarion \& VAINFAS, Ronaldo. Domínios da História, p. 402. 


\section{REFERÊNCIAS}

CARDOSO, Ciro Flamarion e VAINFAS, Ronaldo. Domínios da História. Rio de Janeiro. Editora Campus, 1996.

FUMDHAM. Revista Parque Nacional da Serra da Capivara, PI - Brasil. 1998.

FUMDHAM. Trilhas da Capivara. PI - Brasil. 1998.

GUIDON, Niède. As ocupações pré-históricas do Brasil. In: CUNHA, Manuela Carneiro da. História dos Índios no Brasil. São Paulo, Cia das Letras, 1992.

GUIDON, Niède. Pré-História no Piauí. Revista Horizonte Geográfico, ano 3, no 12, set/out, 1990.

GUIDON, Niède.Tradições rupestres da área arqueológica de São Raimundo Nonato, PI, Brasil. Pernambuco, Revista Clio no 5, vol.1, 1989.

JECUPÉ, Kaka Werá. A terra de mil povos. São Paulo: Peirópolis, 1998.

JUSTAMAND, Michel. As pinturas rupestres no Brasil: uma discussão atual. In: SOUZA, Edgar e GRILLO, José Geraldo Costa. Olhares sobre a História do Brasil. São Paulo: Primeira Impressão, 2008.

JUSTAMAND, Michel. As pinturas rupestres na História e na Antropologia: uma breve contribuição. Francisco Morato: Margê, 2005.

JUSTAMAND, Michel. Comunicar e educar no território brasileiro: uma relação milenar. Embu das Artes: Alexa Cultural, 2012.

JUSTAMAND, Michel. A mulher rupestre: representações do feminino nas cenas rupestres de São Raimundo Nonato - Piauí. Embu das Artes: Alexa Cultural, 2014.

JUSTAMAND, Michel. O Brasil desconhecido: as pinturas rupestres de São Raimundo Nonato - Piauí. Rio de Janeiro: Achiamé, 2010.

JUSTAMAND, Michel. Pinturas rupestres do Brasil: uma pequena contribuição. Embu das Artes: Alexa Cultural, 2007.

JUSTAMAND, Michel. As relações sociais nas pinturas rupestres. Embu das Artes: Alexa Cultural, 2007.

JUSTAMAND, Michel e GRISOLIO, Lilian Marta. Reflexões acerca das políticas educacionais no Brasil: de 1500 à atualidade. In: JUSTAMAND, Michel e GRISOLIO, Lilian Marta. Políticas educacionais: projeto neoliberal em debate. Embu das Artes: Alexa Cultural, 2007.

MARTIN, Gabriela. A pré-história do nordeste do Brasil. Pernambuco. UFPE, 1997. 
MARTIN, Gabriela. Casa santa: Um abrigo com pinturas rupestres do estilo Seridó, no Rio Grande de Norte. Pernambuco, Revista Clio no 5, 1982.

MARTIN, Gabriela. A subtradição Seridó de pintura rupestre pré-histórica do Brasil. Pernambuco, Revista Clio, no 5, 1989.

OLIVEIRA, Ana Claudia de. Neolítico: arte moderna. São Paulo. Ed. Perspectiva, 1987.

OSTROWER, Fayga. In: "A construção do olhar", In: NOVAES, Adauto (org.). O olhar. São Paulo, Cia das Letras, s/data.

PEDROSA, Mário. Forma e percepção estética. São Paulo, EDUSP, 1995.

PEREIRA, Edithe. Arte da Terra: resgate da cultura material e iconográfica do Pará.

PESSIS, A. Imagens da Pré-História. Piauí: Editora FUMDHAM, 2003.

PESSIS, Anne-Marie. In: "Pré-História da região do Parque da Serra Capivara". In: TENÓRIO, Maria Cristina. (org.) Pré-História da Terra Brasilis. Rio de Janeiro, UFRJ, 1999.

PESSIS, Anne-Marie. Apresentação gráfica e apresentação social na tradição Nordeste de pintura rupestre do Brasil. In: Revista Clio, Pernambuco, v. 1 no 5, 1989.

PESSIS, Anne-Marie. Identidade e classificação dos registros gráficos préhistóricos do Nordeste do Brasil. Revista Clio, Pernambuco, v. 1 nº 8, 1992.

PESSIS, Anne-Marie \& GUIDON, Niède. "Registros rupestres e caracterização das etnias pré-históricas", In: VIDAL, Lux (org.). Grafismo Indígena. São Paulo, EDUSP, 1992.

PROUS, André. Arqueologia Brasileira. Brasília. UnB, 1991.

RIBEIRO, Loredana M. Ricardo. In: "Tradição e ruptura na arte rupestre da Lapa do Gigante - Montalvânia/MG”, In: Revista Clio, Pernambuco, Ed. UFPE, v. 1, nº $12,1997$.

ROOSEVELT, A. C. Relatório Preliminar sobre o levantamento e escavações na caverna da Pedra Pintada, Monte Alegre, Pará, Brasil, 1991. 12 folhas impressas.

SEDA, Paulo. A questão das interpretações em arte rupestre no Brasil. In: Revista Clio; Série Arqueológica. Recife. UFPE, v. 1 № 12, 1997.

SCHMITZ, Pedro Inácio. Arte Rupestre no Centro do Brasil. Porto Alegre: Unisinos, 1984. 
SCHMITZ, Pedro Inácio. A questão do paleoíndio. In: TENÓRIO, Maria Cristina (org.). Pré-História da Terra Brasilis. Rio de Janeiro. Ed. UFRJ, 1999.

SILVA, Fabíola Andréa. A Pesquisa Sobre Arte Rupestre: Uma Introdução aos seus Princípios Básicos. Santa Cruz do Sul. Revista do Cepa, 1996. 